\author{
Т. Е. Янко \\ Институт языкознания РАН \\ Государственный институт русского языка им. А. С. Пушкина \\ (Россия, Москва) \\ tanya_yanko@list.ru
}

\title{
НАРЕЧИЕ ДАВНО И ВИДОВРЕМЕННЫЕ ФОРМЫ ГЛАГОЛА: ДАННЫЕ ЗВУЧАЩЕГО КОРПУСА*
}

\begin{abstract}
Двадцать лет назад была высказана гипотеза о том, что в контексте видовременных глагольных значений, соотносящихся с положением дел, ушедшим в прошлое и не оставившим актуальных результатов, наречие давно служит ремой. На роль канонического контекста, соотносящегося с прошлым, прежде всего было выдвинуто общефактическое значение несовершенного вида. В настоящее время в связи с созданием корпусов звучащей речи появилась возможность проверить эту гипотезу на обширном и реальном материале. Коль скоро выразителем коммуникативных значений вообще и ремы в частности служит просодия, она может быть средством доступа к коммуникативной структуре. Анализ просодии предложений с давно в целом подтвердил исходную гипотезу, однако и внес определенные уточнения. Так, было показано, что в предложениях с отрицанием и в предложениях с глаголами речи в контексте общефактического значения несовершенного вида связь положения дел, которое возникло давно, с моментом речи может сохраняться, что не ведет к обязательной рематичности давно. Гипотезы, связанные с рематичностью давно в контексте других видовременных значений (а именно аористического значения и значения имперфекта), настоящее корпусное исследование полностью подтвердило.

Ключевые слова: русский язык, глагольный вид, общефактическое значение несовершенного вида, наречие давно, рема, коммуникативная структура, просодия, звучащий корпус.
\end{abstract}

* Работа поддержана РНФ (проект 18-18-00462 «Коммуникативно-синтаксический интерфейс: типология и грамматика», реализуемый в Государственном институте русского языка им. А.С. Пушкина). 


\section{1. Вступительные замечания}

В статье рассматривается один из случаев взаимодействия лексических, видовременных и прагматических значений. Значения единиц различных уровней анализируются с целью объяснения уникальных коммуникативных особенностей наречия давно.

Ю.Д. Апресян обращает внимание на существование у лексических единиц определенных коммуникативных и просодических свойств [Апресян 2005: 9]. В работах [Апресян 2005: 9; 2006: 111] просодические и коммуникативные параметры слов фигурируют как условия применения правил, моделирующих взаимодействие значений. Так, правила формирования значений могут содержать «ссылки на <..> просодию (особенно на способность - неспособность нести главное фразовое ударение) и на связанную с просодией коммуникативную структуру (как правило, на способность - неспособность быть темой или ремой высказывания)» [Апресян 2005: 9]. В нашей работе ставится задача соотнесения коммуникативных особенностей лексической единицы с ее значением и значением контекста. При этом в качестве маркеров коммуникативной структуры и показателей коммуникативной роли слова рассматриваются просодические параметры. Просодическая структура - это средство выражения коммуникативных значений, и, соответственно, она может служить средством доступа к ним.

Более двадцати лет назад в работе Е. В. Падучевой [1997] было указано, что слово давно не бывает в предложении темой ${ }^{1}$, а в контексте общефактического значения (ниже - ОФ) несовершенного вида (НСВ) давно не только «антитематично», но и «рематично»: Папа покупал эти часы давно. Полужирным шрифтом здесь обозначается акцентоноситель - акцентированное слово (или так называемый носитель главного фразового ударения) ремы. Впоследствии в работах [Янко 2001: 255-269; Yanko 2003] была высказана гипотеза о том, что рематическая полярность у слова давно возникает не только в контексте общефактического, но и в других видовременных контекстах, которые обозначают временну́ю удаленность события от точки отсчета, в частном случае - от момента речи. Видовременные контексты, поддерживающие семантику давности события, удаленности его от акта коммуникации, в соответствии с этой гипотезой должны приводить к рематичности давно. Соответственно, было предложено различать видовременные формы, обозначающие события, которые, даже если и начались давно, сохраняют свою актуальность в точке

${ }^{1}$ В предложении Давно не приходил Ипполит наречие давно служит не темой, как может это показаться на первый взгляд, а компонентом ремы. Это доказывается, в частности, тем, что давно в этом предложении не может нести прототипического акцента темы ИК-3 [Брызгунова 1982: 97-122]. ИК-3 - подъем на ударном слоге словоформы-акцентоносителя плюс падение на заударных слогах, если они есть. У давно заударных нет, но они могут быть сформированы начальными безударными, принадлежащими последующим словоформам. В рассматриваемом примере на начальном давно фиксируется акцент типа ИК-6 [Там же]. Это подъем на ударном слоге плюс ровный тон на заударных, если они есть. Здесь ИК-6 говорит о том, что давно служит начальным компонентом ремы, но не темой. 
отсчета, и формы, которые обозначают ситуацию, имевшую место до точки отсчета и ушедшую в небытие. Так, актуально-длительное (Вася давно сnиm) и перфектное (Вася давно заснул) значения глагола обозначают событие или состояние, которое сохраняется в точке отсчета (например, в момент речи), что не ведет к обязательной рематичности давно. Следовательно, в контексте настоящего времени и при перфектном значении глагола давно может быть как ремой, так и неакцентированным компонентом ремы. Между тем в контексте видовременных значений, таких как значение имперфекта ('событие началось, протекало некоторое время и завершилось до точки отсчета') и аориста ('событие началось и закончилось до точки отсчета'), давно, как и при общефактическом, служит ремой: Это происходило с Васей давно; Это произошло в Москве давно (но не ?Это происходило давно с Васей; ?Это с Васей давно происходило; ?Это произошло давно в Москве); Это было давно; Случилось это давно, еще до войны, где-то в Европе, в маленьком заштатном городке; Разлука с отцзом произошла давно [НКРЯ]. Выявленный набор глаголов со значением имперфекта и аориста - происходило, было, произочло, случилось, приключилось.

Склонностью к роли ремы давно отличается, например, от наречия недавно, которое, наоборот, легко принимает на себя и роль темы: ...недавно был огромный репортаж по Второму каналу [НКРЯ]. В последнем примере недавно служит полноценной начальной темой, несущей соответствующий акцент. Акцентоноситель ремы - словоформа каналу. Давно в таком контексте было бы неграмматичным: *Давно был огромный репортаж по Второму каналу. Для выражения соответствующего смысла в данном контексте в качестве ремы можно было бы использовать только давно: Давно был репортаж по Второму каналу (Репортаж по Второму каналу был давно). Что же касается недавно, то оно может быть не только темой, но и ремой: Я в этом отряде недавно [НКРЯ].

Таким образом, давно обозначает событие или состояние, удаленное от говорящего во времени, а идея о том, что языковые единицы, входящие в состав предложения на разных уровнях, которые имеют референцию к странному, неожиданному, отличному от нормы, далекому от говорящего (во времени и в пространстве), чужому по отношению к нему, имеют рематическую полярность, и двадцать лет назад не была новой. Ср. идеи, высказанные по поводу коммуникативной роли «рематических» слов редко и мало [Булыгина, Шмелев 1988; 1997: 203], редкий [Падучева 1989: 21], задолго (в отличие от незадолго) [Богуславский 1996: 63], придаточных предложений с чтобы с так называемой антицелью, которые в отличие от стандартных предложений цели могут быть только ремой: ...в 1827 году он станет первым президентом освобожденной Греции, чтобы в 1831-м погибнуть за нее [НКРЯ].

Существует универсальный набор контекстов, нейтрализующих рематическую полярность лексических единиц, таких как давно, редко и мало. К таким контекстам относится коммуникативная нерасчлененность и контраст. Так, в примере $<$ Вы не узнаете меня? Бабка закивала головой. - Да как же, узнала теперь. $>^{2}$

${ }^{2}$ В угловые скобки помещается релевантный для анализа предложений с давно контекст. 
Редко заходишь, деточка [НКРЯ] предложение редко заходишь представляет собой цельную рему, содержащую объяснение, почему старая женщина не узнала девочку. В соответствии с известными принципами выбора акцентоносителя в предложении, которое представляет собой цельную рему, акцентоносителем ремы служит не наречие ${ }^{3}$. Аналогично рематический акцент может покидать слово с рематической полярностью в контексте контраста: Интересным оказался <..> вывод, полученный при исследовании рекордсменов-итангистов: дылиать нужно не редко и глубоко, а часто и поверхностно [НКРЯ]. В последнем примере с контрастной конструкцией не..., $a$ акцентоносителем ремы служит словоформа поверхностно, а не слово с рематической полярностью редко. Коммуникативная нерасчлененность и контраст возмущают семантические и коммуникативные законы взаимодействия значений [см.: Янко 2001: 270].

В настоящее время в связи с созданием звучащих корпусов устной речи открылась возможность проверить гипотезы относительно коммуникативных предпочтений лексических единиц на реальном и представительном материале. Коль скоро просодия дает доступ к коммуникативной структуре, анализ звучащего текста позволяет уточнить, какие конкретно коммуникативные роли играет наречие давно в коммуникативной структуре русского предложения. Источником материала послужил мультимедийный подкорпус «Национального корпуса русского языка» [НКРЯ], содержащий звучащие записи. Это лекции, доклады, пресс-конференции, телепередачи и фильмы. На контексты с давно в мультимедийном корпусе приходится около 1500 примеров. Результат поиска по ключевому слову давно и составил рабочий массив исследования.

Забегая вперед, можно констатировать, что корпусный анализ (который был поддержан инструментально ${ }^{4}$ ) в целом подтвердил гипотезу о рематической полярности давно, однако расширение эмпирической базы внесло важные уточнения. Так, кардинальную поправку внес анализ атрибутивных оборотов, которые ранее отдельно не рассматривались. Было показано, что в составе определительных придаточных и оборотов (причастий и прилагательных с зависимыми) давно может принадлежать не только реме, но и быть компонентом темы: От первого, раннего, давно забытого брака у него осталась дочка [НКРЯ]. Здесь наречие давно входит в состав темы от первого, раннего, давно забытого брака. Акцентоноситель темы - существительное брака. Поясним, что тем в предложении может быть более одной. Акцентоноситель ремы здесь - словоформа дочка. Рема - осталась дочка, у него - вторая тема.

При анализе устного массива коммуникативная роль давно устанавливалась в соответствии с известными просодическими средствами выражения собственно рем (акцентоносителей рем), компонентов рем и тем. Так, рема повествовательного предложения маркируется нисходящим движением тона на ударном слоге

3 О принципах выбора акцентоносителя в нерасчлененном предложении см. [Янко 2008: 46].

${ }^{4}$ Анализ просодического рисунка высказываний проводился с помощью компьютерной системы анализа звучащей речи «Praat» [http://www.praat.org/]. 
словоформы - акцентоносителя ремы плюс падением частоты тона на заударных слогах, если они есть (ИК-1 или ИК-2 — по [Брызгунова 1982]). У давно заударных слогов нет, но они могут быть сформированы безударными слогами словоформ, следующих за давно. К средствам выражения компонентов рем (но не собственно рем) относятся акцент типа ИК-6 [Там же] и безакцентная (т. е. не несущая релевантных движений тона) артикуляция. Подъемами - ИК-3 и ИК-6 - маркируются тема и дискурсивная незавершенность, а также, дополнительно, акцентом ИК $-4^{5}$ - некоторые виды дискурсивной незавершенности (детали семантики и просодии дискурсивной незавершенности см. в [Янко 2008: 128-170; 2018]).

\section{2. Результаты анализа материала}

Анализ просодии примеров с давно из мультимедийного подкорпуса [НКРЯ] показал, что за исключением атрибутивных оборотов давно действительно служит либо ремой повествовательного предложения (Тебе ж давно предлагали Катерину грохнуть [НКРЯ]; на давно-рему приходится около половины всех рассмотренных примеров), либо компонентом ремы (Они вообще уже давно ничего не думаюm [НКРЯ]; около трети выявленных встречаемостей давно). В круг рематических употреблений давно мы также условно включаем давно в роли неизвестного данет-вопроса, например: Bbl в бельевую давно заглядывали? [НКРЯ]. Отличие между ремой как коммуникативным компонентом, формирующим иллокутивную силу сообщения, и неизвестным вопроса, формирующим иллокутивную силу вопроса, безусловно, весьма существенное, но в данном случае это различие не принципиально: и то и другое служит собственно иллокутивным компонентом речевого акта определенного вида. Таким образом, неизвестное да-нет-вопроса мы при анализе рематичности давно рассматриваем как аналог ремы. Остальные примеры из корпуса - это в основном давно в составе конструкций, в которых рематическая полярность давно снимается: когда-то давно, как-то давно, очень давно, давныл-давно, давно-давно, уже давно, не так давно. Из конструкций и лексем, производных от давно, наследует рематичность давно только наречие давненько (давнехонько). На то, что давнылм-давно в отличие от давно может быть не только ремой, но и темой, впервые обратил внимание Ю. Д. Апресян еще в 1988 г. [Апресян 1988] $]^{6}$. Семантическое объяснение утраты рематичности давно в производных словах и конструкциях было предложено в нашей работе [Янко 2001: 265]7 .

${ }^{5}$ ИК-4 представляет собой падение или ровный низкий тон на ударном слоге носителя акцента плюс подъем на заударных слогах, если они есть. Если заударных слогов нет, интегральное нисходяще-восходящее движение тона фиксируется на последнем или единственном слоге носителя акцента [Брызгунова 1982: 97-122].

${ }^{6}$ Cр. примеры из корпуса: ...любили мы, конечно, друг друга давнымм-давно (рема) vs. Когдато давным-давно (тема) жил в этом селе один богатый мельник...[НКРЯ].

7 Сущность объяснения коммуникативных различий между давно и давным-давно (когда-то давно, очень давно) состоит в том, что в предложениях с конструкциями, производными от давно, имеется дополнительный компонент значения, который говорит о существовании события: ‘Было 


\section{1. Давно в контексте глаголов было, случилось, происходило}

Что касается глаголов было, случилось и произошло в так называемом аористическом значении совершенного вида ('нечто произошло и не оставило актуальных результатов’), то все имеющиеся примеры, во-первых, действительно содержат давно в функции ремы, во-вторых, не допускают сдвигов «рематической» (нисходящей в повествовательном предложении) просодии на другую словоформу в клаузе. Таким образом, гипотеза о рематичности давно в контексте аористических было, произошло и случилось подтверждается. Употреблений глагола происходило в так называемом имперфектном значении в звучащем подкорпусе [НКРЯ] не обнаружено, но примеры, которые удается интерпретировать и без обращения к звучащему материалу, можно найти в основном (письменном) корпусе: ...coбblтия, о которых мы рассуждаем, происходили давно... [НКРЯ]. Анализ материала с давно плюс значение имперфекта также поддерживает гипотезу о рематичности давно в контексте прошлого.

Между тем давно в контексте общефактического значения несовершенного вида (ОФ НСВ) обнаруживает более сложную картину, которая говорит о том, что в этом случае гипотеза о рематичности давно требует уточнений.

\section{2. Давно и общефактическое значение НСВ}

Релевантные контексты для давно плюс общефактическое НСВ в имеющемся рабочем массиве представлены следующими основными классами:

1) повествовательные предложения без отрицания с глаголами разнообразной семантики, кроме глаголов речи (с сентенциальным дополнением);

2) да-нет-вопросы;

3) повествовательные предложения с отрицанием;

4) повествовательные предложения с глаголами речи и сентенциальным дополнением.

\subsection{1. Повествовательные предложения без отрицания}

Повествовательные предложения без отрицания с глаголами, которые не являлись бы глаголами речи с сентенциальным дополнением, в рабочем массиве представлены небольшим количеством примеров: <-A это дяди Шурика сапожки! - Какого Шурика? - Какого-какого. Будто не знаешь,> какой у нас давно ночевал [НКРЯ]. Примеры полностью соответствуют положению о рематичности давно в контексте ОФ НСВ.

так, что Р. Р было давно'. Квантификация существования снимает обязательную рематичность, присущую давно (cp. пару редко vs. изредка с тем же соотношением коммуникативных ролей и структурой толкования значений). 


\subsection{2. Да-нет-вопросьи}

В $\partial a$-нет-вопросах представлены глаголы самой разнообразной семантики: - Вы в бельевую давно заглядывали?; Ты ей памперсы давно менял?; <Посмотри на себя, во что ты превратилась!> Взвешивалась давно?; <И себе налей.> Ела дав$\boldsymbol{\mu \boldsymbol { o }}$ ? [НКРЯ]. Эти примеры без исключения также поддерживают гипотезу о рематичности давно в контексте ОФ НСВ. М.Я. Гловинская [1982: 140] замечает, что в вопросительном предложении общефактическое значение у глагола НСВ возникает чаще, чем в повествовательном, и приводит такой пример: Дождь прекращался (актуально-длительное) vs. Дождь прекращался? (общефактическое). И.Б. Шатуновский [2009: 146] дает этому следующее объяснение. Он считает, что да-нетвопросы с общефактическим значением глагола более частотны, чем повествовательные предложения, потому что для вопроса скорее, чем для повествовательного предложения, находится дискурсивная интерпретация, или то, что должно служить естественным обоснованием совершения речевого акта. У повествовательного предложения с глаголом в ОФ НСВ должно быть логическое продолжение: Поступал, но провалился; Он оканчивал университет, и теперь он образованный человек; Встречался с Романом Якобсоном, и теперь у нас есть что вспомнить. Вопросы же с общефактическим относительно независимы от контекста: В Кутаиси давно был? [НКРЯ]. Таким образом, вопросы с ОФ НСВ должны встречаться чаще, чем повествовательные предложения. Материал корпуса это полностью подтверждает.

\subsection{3. Повествовательные предложения и да-нет-вопросы с отрицанием}

В повествовательных предложениях и $\partial а$-нет-вопросах с отрицанием также представлены разнообразные глаголы: <Так мы ж договорились ушами... Форму потерял.> Давно не шевелил; Давно не пробовала; Давно мы не сталкивались с гвардейцами кардинала! [НКРЯ]. Примеры с отрицанием говорят о том, что контекст «общефактическое плюс отрицание» не приводит к обязательной рематичности давно. В таком контексте давно может быть не только ремой, но и компонентом ремы: Давно не пробовала; Давно не шевелил.

Утрата обязательной рематичности давно в контекстах с отрицанием требует объяснения. Если исходить из того, что к рематичности давно ведет не собственно ОФ НСВ, а семантика удаленности релевантного положения дел от точки отсчета и отсутствие актуальных результатов в настоящем, то это условие в контекстах с отрицанием не выполняется. Контекст отрицания говорит о том, что отсутствие некоторого положения дел сохраняется начиная от удаленной точки во времени вплоть до точки отсчета, потому что при отрицании ситуация концептуализуется не как давность произошедшего события определенного типа, а как то, что в течение длительного времени подобное событие не имело места, возможно, включая и точку отсчета: Сынок, чего-то я давно не видел твой дневник [НКРЯ]. Последний пример означает, что отец не видел дневника сына долгое время и, весьма возможно, продолжает не видеть его и в момент речи. 
Существенно, что интерпретация давности события определенного типа как отсутствие наступления его новых инстанций (шевеления ушами, стычек с гвардейцами кардинала, приема лекарства и прогулок с собакой) возможна только для тех ситуаций, которые понимаются как способные (или даже склонные) к повторению, дискретные (по М. Я. Гловинской [1982: 134]): из того, что нечто было давно, может следовать, что после того, как некое событие произошло, на протяжении долгого времени ни одна из инстанций события такого рода не имела места. Однако потенциальной повторяемости события может быть недостаточно для установления денотативного тождества ситуаций $P$ было давно и $P$ давно не было. При интерпретации может оказаться существенной и онтологическая сущность события. Так, из Обедал я давно можно сделать вывод, что пора поужинать, а из Давно не обедал - что долгое время приходилось питаться всухомятку, без супа и компота. Эта пара примеров не соответствует формуле $P$ было давно $\approx P$ давно не было. Кроме того, запрет на отрицательную интерпретацию ситуации давности может возникнуть и при конкретной референции участника ситуации. Так в предложении Папа давно покупал эти часы замена на ?Папа давно не покупал эти часы практически невозможна, потому что здесь идет речь не о каких-то часах вообще, а об одних и тех же, определенных часах.

Таким образом, можно заключить, что русским языком для указания на временну́ю удаленность разработана замещающая концептуальная модель, которая означает, что в течение длительного времени подобного события не было. Отсутствие события понимается как особое положение дел, которое в отличие от абсолютной давности события может восстанавливать связь некоего положения дел (теперь уже не самого события, а его отсутствия) с моментом речи. Как показывают данные корпуса, модель с отрицанием в повествовательном предложении с давно более частотна, чем модель без отрицания.

Соответственно, при установлении условной эквивалентности положительной и отрицательной интерпретаций предложений с давно (Видел дневник давно $\approx$ Давно не видел дневника) решающую роль играют два фактора: это референциальный статус различных участников ситуации и ее онтологическая структура. При обсуждении ОФ НСВ об этих факторах говорят многие авторы [см., например: Гловинская 1982: 134-135]. Определенность участников, времени и места события в целом препятствует возникновению общефактического значения. Между тем в связи со структурой жизненной - внеязыковой - ситуации добавим, что если представить себе нестандартный случай, при котором один раз купленные часы по какойлибо причине утрачиваются и становится возможной их повторная покупка, как если бы папа работал антикваром, регулярно скупающим и продающим старые часы, то предложение Папа давно не покупал эти часы может обрести смысл.

Итак, примеры с отрицанием говорят о том, что контекст ОФ НСВ не служит абсолютным условием рематичности давно. Того, что глагол принимает общефактическое значение, еще недостаточно для того, чтобы давно с обязательностью было ремой. Решающим фактором для рематичности давно служит отсутствие актуальности события, его прямых последствий или его результата в точке отсчета. 
2.2.4. Повествовательнье предложения с глаголами речи и сентенциальньм дополнением

В повествовательных предложениях с глаголами речи в общефактическом значении (говорить, предлагать, объяснять), которые представлены в рабочем корпусе, давно воплощено в виде ремы: Я же давно говорил, что <..> возникнет и виртуальный брак в сети, и виртуальные дети; Она мне давно про тебя разъясняла, что ты в Аглаю Епанчину как кошка влюблен; Я ей давно говорила: не бросишь его, прокляну; Я давно говорил: попугаи у нас не приживутся [НКРЯ].

Между тем в предложениях анализируемого класса перенос рематического акцента с давно на другую словоформу возможен: соответственно, рематичность давно в этих контекстах не абсолютна.

Обратимся к глаголам с сентенциальным дополнением. Особенность глаголов передачи информации состоит в том, что они имеют импликатуру сохранения информации в сознании получателя после того, как акт передачи информации состоялся. Если А сказал В, что Р, то с известной вероятностью В будет знать, что Р. Сохранение информации в сознании получателя не препятствует тому, чтобы А говорил В о Р вновь и вновь: много раз говорил, что Р, не раз говорил, всегда говорил. Однако в данном случае итерация акта говорения может быть связана не с сообщением действительно новой информации, а с повторением того, что уже известно, например с целью напомнить, заставить слушающего лишний раз задуматься над проблемой.

Таким образом, то, что контекст глаголов речи в ОФ НСВ благоприятствует рематичности давно, мы объясняем тем, что если локутивный акт (факт говорения) имел место по крайней мере один раз в прошлом и это было давно, то это может приводить к рематичности давно. Здесь рематичность связана с ассертивной частью значения предложения, а именно с локутивным актом. Между тем рематичность давно здесь не абсолютна, ибо, как уже говорилось, большинство имеющихся примеров допускает перенос акцента с давно на глагольную группу. Возможную утрату рематичности давно мы объясняем тем, что в предложениях с глаголами передачи информации имеется импликатура, состоящая в том, что локутивный акт достиг своей цели и был воспринят (слушающий знает, что Р), что может создавать эффект сохранения положения дел в точке отсчета. Это, наоборот, может отменять рематичность давно.

Рассмотрим возможный перенос акцента с давно на другую словоформу в предложении. Так, в примере из речи министра иностранных дел давно - рема: ... мы давно говорили, что искоренение терроризма < .. > является <..> более важной задачей, чем смена режима [НКРЯ]. В записи звучащего примера нисходящий акцент приходится на давно. В этом случае сообщение понимается так, что идея о борьбе с терроризмом высказана уже давно и существенна давность ее возникновения. Между тем, поскольку эта идея актуальна до момента речи, давно может уступать роль ремы глагольной группе с сентенциальным дополнением. Акцент ремы в таком случае покидает давно и перемещается на дополнение. Таким 
образом, в этом примере с изначальным давно-ремой перенос функции ремы с давно на глагольную группу оказывается возможным. При утрате словоформой давно рематичности пример получает следующую артикуляцию: давно произносится безакцентно, на глаголе говорили фиксируется восходящий акцент незавершенности, затем в сентенциальном дополнении формируются акценты, соответствующие его синтаксической и коммуникативной структуре. Акцентоносителем ремы становится словоформа режима: ...мы давно говорили, что искоренение терроризма <..> является < .. > более важной задачей, чем смена режима. В результате рематический акцент покидает давно.

Эффект сохранения информации может объяснить и то, что предложения с глаголами речи не всегда имеют отрицательные корреляты. Поскольку большинство глаголов речи обозначает ситуацию передачи и сохранения в памяти слушающего информации, которую сообщил ему говорящий, а информация, как известно, в идеале сохраняется, повторное сообщение той же информации оказывается если не невозможным, то нелогичным. Мы предполагаем, что сохранение единожды полученной информации в сознании слушающего ограничивает употребление глаголов говорения с отрицанием при давно: ?давно не говорил / не рассказывал тебе, что Р (ср. давно не приходил, давно не приезжал, давно не ночевал дома, давно не шевелил ушами).

$* * *$

Анализ звучащего корпуса показал, что контекст общефактического значения несовершенного вида русского глагола не служит абсолютным условием рематического функционирования наречия давно в предложении. Общефактическое значение глаголов с отрицанием и глаголов речи с сентенциальным дополнением допускает утрату давно рематической функции. Это объясняется семантикой сохранения некоторого положения дел, начиная от удаленного момента в прошлом вплоть до точки отсчета. Вопрос о том, существуют ли другие классы ситуаций, обозначаемых глаголом в общефактическом значении НСВ, кроме ситуаций, выражающихся глаголом с отрицанием или глаголом речи с сентенциальным дополнением, которые лишают давно обязательной рематичности, мы оставляем открытым. Возможно, при дальнейшем исследовании и расширении корпуса будут обнаружены новые контексты утраты наречием давно рематического акцента в контексте общефактического. В любом случае можно заключить, что условие рематичности давно следует формулировать не терминах общефактического значения, а в терминах временно́й удаленности события и его результатов от точки отсчета.

\section{Литература}

Апресян Ю.Д. Типы коммуникативной информации для толкового словаря // Язык: система и функционирование / под ред. Ю. Н. Караулова. М. : Наука, 1988. C. 10-22. 
Апресян Ю.Д. Правила взаимодействия значений и словарь // Русский язык в научном освещении. 2005. № 1 (9). С. 7-45.

Апресян Ю.Д. Основания системной лексикографии // Апресян В.Ю., Anресян Ю. Д., Бабаева Е. Э., Богуславская О. Ю., Иомдин Б. Л., Крылова Т. В., Левонтина И.Б., Санников А. В., Урысон Е. В. Языковая картина мира и системная лексикография / отв. ред. Ю. Д. Апресян. М. : Языки славянских культур, 2006. С. 33-162.

Богуславский И. М. Сфера действия лексических единиц. М. : Языки русской культуры, 1996. $464 \mathrm{c}$.

Брызгунова Е. А. Интонация // Русская грамматика : в 2 т. / отв. ред. Н. Ю. Шведова. М. : Наука, 1982. Т. 1. С. 97-122.

Бульгина Т.В., Шмелев А.Д. Несколько замечаний о словах типа несколько (к описанию квантификации в русском языке) // Язык: система и функционирование / под ред. Ю. Н. Караулова. М. : Наука, 1988. С. 44-54.

Булыгина Т.В., Шмелев А.Д. Языковая концептуализация мира (на материале русской грамматики). М. : Языки славянских культур, 1997. 577 с.

Гловинская М.Я. Семантические типы видового противопоставления русского глагола. М. : Наука, 1982. 155 с.

НКРЯ - НКРЯ - Национальный корпус русского языка [Электронный реcypc]. URL: http://ruscorpora.ru

Падучева $E . B$. К интонационной транскрипции для предложений произвольной синтаксической сложности // Вопросы кибернетики. Вып. 159 : Семиотические исследования / под ред. В. А. Успенского. М. : Изд-во АН СССР, 1989. С. 18-29.

Падучева Е.В. Давно и долго // Логический анализ языка: Язык и время / отв. ред. Н. Д. Арутюнова, Т. Е. Янко. М. : Индрик, 1997. С. 253-267.

Шатуновский И.Б. Проблемы русского вида. М. : Языки славянских культур, 2009. $351 \mathrm{c}$.

Янко T.E. Коммуникативные стратегии русской речи. М. : Языки славянских культур, 2001. 384 с.

Янко T. Е. Интонационные стратегии русской речи в сопоставительном аспекте. М. : Языки славянских культур, 2008. 312 с.

Янко T. Е. Речевые акты в структуре связного дискурса: показатели незавершенности по данным корпусов звучащей речи // Компьютерная лингвистика и интеллектуальные технологии : сб. ст. по материалам ежегодной Международной конференции «Диалог-2018». Вып. 17 (24) / гл. ред. В.П. Селегей. М. : Изд-во РГГУ, 2018. С. 791-802.

Yanko T. The Communicative Effects on the Interaction between the Verbal Aspectual Categories and Temporal Adverbials in Russian // Journal of Slavic linguistics. 2003. Vol. 11. № 11. P. 199-215. 


\section{T.E. Yanko}

Institute of Linguistics of the Russian Academy of Sciences

Pushkin State Russian Language Institute

(Russia, Moscow)

tanya_yanko@list.ru

\section{RUSSIAN ADVERB DAVNO 'LONG AGO' AND ASPECTUAL VERB FORMS: SPOKEN CORPORA DATA}

Twenty years ago, it was hypothesized that in the context of the aspectual forms of Russian verbs relating to past events and having no reference to the real results of action at the moment of speech the adverb davno 'long ago' is the rheme. As a canonical context to refer to the past the general factual meaning of the Russian imperfective aspect was singled out. Presently, the new sound corpora give an opportunity to verify this hypothesis on extensive and real material. Since the prosody of oral speech is the main means of expressing the communicative structure as a whole and the rheme in particular, it can open the access to the communicative structure. The prosodical analysis of the spoken sentences with davno has on the whole verified the main hypothesis, but some interesting specifications have also appeared. It has been demonstrated that in sentences with negation and in sentences with verbs of speech in the general factual meaning, the state of things that arose long ago may keep up to the point of reference (moment of speech). This, therefore, does not obligatorily demand davno to be the rheme. In contrary to what was meant before, davno in composition with the general factual meaning of the imperfective case is not an absolute condition for davno to function as the rheme.

Key words: the Russian language, general factual, prosody, temporal adverbs, verb aspect, rheme, spoken corpora.

\section{Acknowledgements}

This study has been supported by the Russian Science Foundation, project No. 8-1800462 "The communicative-syntax interface: typology and grammar" realized at Pushkin State Russian Language Institute.

\section{References}

Apresyan Yu.D. [The Types of Communicative Information for an Explanatory Dictionary]. Yazyk: sistema i funktsionirovanie [Language: It's System and Functions]. Yu.N. Karaulov (Ed.). Moscow, Nauka Publ., 1988, pp. 10-22. (In Russ.)

Apresyan Yu.D. [Rules for the Interaction of Meanings and Vocabulary]. Russkii ya$z y k v$ nauchnom osveshchenii, 2005, No. 1 (9), pp. 7-45. (In Russ.)

Apresyan Yu.D. [The Base for System Lexicography]. Apresyan V.Yu., Apresyan Yu.D., Babaeva E.E., Boguslavskaya O.Yu., Iomdin B.L., Krylova T.V., 
Levontina I. B., Sannikov A. V., Uryson E.V. Yazykovaya kartina mira i sistemnaya leksikografiya [Language Worldview and System Lexicography]. Yu.D. Apresyan (Ed.). Moscow, Yazyki slavyanskikh kul'tur Publ., 2006, pp. 33-162. (In Russ.)

Boguslavskii I. M. Sfera deistviya leksicheskikh edinits [The Scope of Lexical Units]. Moscow, Yazyki russkoi kul'tury Publ., 1996, 464 p.

Bryzgunova E. A. [Intonation]. Russkaya grammatika [Russian Grammar, Vol. 1]. N.Yu. Shvedova (Ed.). Moscow, Nauka Publ., 1982, pp. 97-122. (In Russ.)

Bulygina T. V., Shmelev A.D. [Some Remarks on the Words Like neskoljko 'Some, a Few' (To the Description of Quantification in Russian)]. Yazyk: sistema i funktsionirovanie [Language: It's System and Functions]. Yu.N. Karaulov (Ed.). Moscow, Nauka Publ., 1988, pp. 44-54. (In Russ.)

Bulygina T.V., Shmelev A.D. Yazykovaya kontseptualizatsiya mira (na materiale russkoi grammatiki) [Language Conceptualization of the World (Based on Russian Grammar)]. Moscow, Yazyki slavyanskikh kul'tur Publ., 1997, 577 p.

Glovinskaya M.Ya. Semanticheskie tipy vidovogo protivopostavleniya russkogo glagola [Semantic Types of the Aspectual Opposition of the Russian Verb]. Moscow, Nauka Publ., 1982, 155 p.

Natsional'nyi korpus russkogo yazyka [The National Corpus of the Russian Language]. Available at: http://ruscorpora.ru (accessed 12.02.2020).

Paducheva E. V. [On the Intonation Transcription of Sentences with Random Syntactic Complexity]. Voprosy kibernetiki. Vyp. 159. Semioticheskie issledovaniya [Problems of Cybernetics. Iss. 159: Semiotic Researches]. V. A. Uspenskii (Ed.). Moscow, USSR AS Publ., 1989, pp. 18-29. (In Russ.)

Paducheva E. V. [Davno 'Long Ago' and Dolgo 'for a Long Time']. Logicheskii analiz yazyka: Yazyk i vremya [Logical Analysis of Language: Language and Time]. N.D. Arutyunova, T.E. Yanko (Eds.). Moscow, Indrik Publ., 1997, pp. 253-267. (In Russ.)

Shatunovskii I. B. Problemy russkogo vida [Problems of the Russian Aspect]. Moscow, Yazyki slavyanskikh kul'tur Publ., 2009, 351 p.

Yanko T. The Communicative Effects on the Interaction between the Verbal Aspectual Categories and Temporal Adverbials in Russian. Journal of Slavic linguistics, 2003, Vol. 11, No. 11, pp. 199-215.

Yanko T. E. Kommunikativnye strategii russkoi rechi [The Communicative Strategies of Russian Speech]. Moscow, Yazyki slavyanskikh kul'tur Publ., 2001, 384 p.

Yanko T.E. Intonatsionnye strategii russkoi rechi v sopostavitel'nom aspekte [Intonation Strategies of Russian Speech from a Comparative Perspective]. Moscow, Yazyki slavyanskikh kul'tur Publ., 2008, 312 p.

Yanko T.E. [Speech Acts in the Structure of Coherent Discourse: the Markers of Incompleteness According to Data of the Spoken Speech Corpora]. Komp'yuternaya lingvistika i intellektual'nye tekhnologii: sb. st. po materialam ezhegodnoi Mezhdunarodnoi konferentsii «Dialog-2018». Vyp. 17 (24) [Computer Linguistics and Intelligent Technologies: A Collection of Articles Based on the Materials of the International Conference Dialog-2018. Iss. 17 (24)]. V.P. Selegei (Ed.). Moscow, Russian St. Univ. for the Humanities Publ., 2018, pp. 791-802. (In Russ.) 